\title{
Examining the COVID-19 Response of Canadian Grantmaking Foundations: Possibilities, Tensions, and Long-Term Implications
}

\author{
Adam Saifer, Jean-Marc Fontan, \& Charles Duprez \\ Université du Québec à Montréal \\ Isidora G. Sidorovska \\ University of Waterloo \\ Manuel Litalien \\ Nipissing University
}

\begin{abstract}
This article explores how Canadian philanthropic foundations with social justice mandates responded to the social and economic impacts of the COVID-19 pandemic by loosening restrictions for grantees; collaborating on new initiatives; elevating grassroots knowledge; and balancing short- and long-term priorities. This response, however, revealed a series of tensions in the dominant pre-COVID-19 philanthropic model—specifically, as a mechanism to address the social, economic, and ecological crises that predate COVID-19. The early pandemic response of grantmaking foundations can therefore serve as a model for what a more democratic, agile, collaborative, and justice-oriented philanthropic sector can look like.

\section{RÉSUMÉ}

Cet article examine la réponse de fondations philanthropiques canadiennes aux enjeux de justice sociale pendant la pandémie de COVID-19. Elles l'ont fait en assouplissant les exigences exigées aux donataires; en collaborant autour de nouvelles initiatives; en priorisant l'expertise des communautés; et en équilibrant les priorités à long et à court terme. Cette réponse révèle les tensions inhérentes au modèle classique de l'action philanthropique, particulièrement dans les façons de répondre aux crises sociales, économiques et écologiques. La réponse actuelle fournit des bases solides pour repenser le modèle d'action du secteur philanthropique subventionnaire afin qu'il soit plus démocratique, plus collaboratif et plus axé sur la justice.
\end{abstract}

Keywords / Mot clés : Grantmaking foundations; COVID-19; Canadian philanthropic sector; Equity and social justice; Organizational change / Fondations subventionnaires; COVID-19; Secteur philanthropique canadien; Équité et justice sociale; Changement organisationnel 


\section{Saifer, Sidorovska, Litalien, Fontan, \& Duprez (2021)}

\section{INTRODUCTION}

In the early days of the COVID-19 pandemic, Canada plunged into a deep socio-economic crisis. Following a series of provincially mandated lockdowns, as well as the reduction of economic and social activities to core "essential services," unemployment and social assistance rates soared while key socio-economic indicators plummeted. Unlike during the Great Depression of the 1930s, however, the magnitude of the crisis was mitigated by a range of interventions by public legislators at all levels of government. Federal, provincial, and territorial governments directly injected billions of dollars into support measures for individuals (e.g., direct financial support through programs such as the Canada Emergency Response Benefit, as well as changes to Employment Insurance); businesses (e.g., wage and rent subsidies and interest-free loans), and nonprofit organizations (e.g., additional public investment in frontline organizations that address homelessness, food insecurity, disability issues, or mental health, among others). Beyond these state-led and statefunded supports, however, the COVID-19 pandemic also generated an ambitious response throughout Canadian society, from the mobilization of individuals through lockdown and social distancing measures, to nonprofits and charities adapting on the fly to meet increased demand. And while preliminary data suggests a steep decline in individual charitable giving (Imagine Canada, 2020a), there has been a prominent uptick in grassroots community-driven organizing in the form of mutual aid networks and the "caremongering" movement (Seow, McMillan, Civak, Bainbridge, van der Wal, Haanstra, Goldhar, \& Winemaker, 2021).

Amid this unprecedented degree of public expenditure and community mobilization, many within the philanthropic sector quickly expressed a desire and commitment to contribute to the collective effort. On March 26, 2020, Community Foundations of Canada, Philanthropic Foundations Canada, Environment Funders Canada, and The Circle on Philanthropy and Aboriginal Peoples in Canada-four key member organizations within the sector-issued a joint statement outlining how grantmaking foundations should engage with their grantees during, and beyond, the COVID-19 crisis. Aptly titled "We're All in This Together," the document touched on several themes organized around principles of flexibility, collaboration, capacity-building, and supporting advocacy work. The four signatories further "invite[d] foundations across the country to adapt these [principles] to their context and join us in their implementation so that the organizations we fund can carry on their important work in our communities throughout and after the crisis" (Community Foundations of Canada et. al., 2020, para. 2). This joint call signalled a dramatic departure from the "snail-like" reflex (i.e., quickly returning to the safety and comfort of one's shell) that characterized the response of philanthropic foundations during the $2008 \mathrm{fi}-$ nancial crisis (Giving USA Foundation, 2009; Johnson, Rauhaus, \& Webb-Farley, 2020; Reich \& Wimer, 2012). It also invigorated a process of reflecting on -and reimagining how-organized philanthropy can and should deploy the roughly CDN\$85 billion in assets that Canadian foundations currently possess amidst the COVID-19 pandemic.

The article contributes to the emerging literature on the Canadian philanthropic sector's response to the social and economic ramifications of COVID-19 (see Akingbola, 2020; Barr, 2020; Cho \& Kurpierz, 2020; Lasby, 2020; McMullin \& Raggo, 2020). It pays particular attention to major changes in policy and practice instituted by grantmaking foundations with equity and social justice mandates, ${ }^{1}$ and the ways in which this crisis response may influence the evolution of philanthropic foundations post-COVID-19. Specifically, it seeks to address the following research questions:

1. In what ways have Canadian grantmaking foundations committed to equity and social justice responded to the COVID-19 crisis?

2. What has this response revealed about the dominant (pre-COVID-19) philanthropic model, particularly regarding its capacity to contribute to movements for equity and social justice?

3. What are the implications of these revelations for the philanthropic sector in terms of policy, practice, and research post-COVID-19? 


\section{Saifer, Sidorovska, Litalien, Fontan, \& Duprez (2021)}

The article draws on both case study methods and semi-structured interviews to look beyond the rhetoric and discourse coming out of the sector, toward concrete actions taken-as well as difficulties and challenges faced-by specific grantmaking foundations and the grantees they support. It argues that, in the early months of the COVID-19 pandemic, grantmaking foundations veered away from a dominant philanthropic model that is, among other things: relatively conservative; self-preserving through investment in growth-oriented endowments (Barkan, 2013; Jensen, 2019) and an unambitious disbursement quota (Boggild \& Hawkesworth, 2017); managerial and project-oriented (Benjamin, 2010); and characterized by top-down power relations between funders and grantees (Chaidez-Gutierrez \& Fischer, 2013; Fairfield \& Wing, 2008). By demanding a departure from this "business as usual" approach to grantmaking, the COVID-19 crisis has made room for critical reflection on what can and should be transformed across the sector to create greater synergy between the philanthropic ecosystem's various components, and to reimagine the sector as a more equitable, democratic, ambitious, and responsive social policy force in Canadian society.

The remainder of this article is divided in four sections. The first section provides an overview of the methodological approach to this study, as well as the dual qualitative data sets it draws on. The second section presents some of the key changes in grantmaking policy and practice in response to the pandemic, which are organized into four overarching themes: loosening rules, regulations, and restrictions for grantees; collaborating on new programs and initiatives; elevating grassroots knowledge and expertise; and balancing short and long-term priorities and goals. The third section critically examines these changes, discussing some of the major tensions they reveal about organized philanthropy in Canada, specifically in relation to the sector's capacity to contribute to movements for equity and social justice. Finally, the article concludes by asking whether these changes can provide a model for how the sector can address the manifold social and economic crises in Canadian society that preceded_and will exist after-COVID-19.

\section{METHODOLOGY}

This article draws on interview data from two distinct qualitative research projects (which will hereafter be referred to as Project A and Project B) led by two different researchers conducted as part of the Canadian Philanthropy Partnership Research Network (PhiLab) around the philanthropic sector's response to the COVID-19 crisis. Project A focused on the pandemic response of grantmaking foundations, with particular attention paid to the creation of new foundation-led initiatives and collaborations in pursuit of equity and social justice during the early stages of the pandemic. This case study research aimed to supplement existing macro-level analyses of the COVID-19 response of grantmaking foundations (e.g., Lasby, 2020; Philanthropic Foundations Canada, 2020), by documenting ongoing processes, policies, and practices in real time through an ad-hoc assemblage of semi-structured interviews with key voices within—or adjacent to-specific foundationled initiatives or collaborations. This data was then used to inform four descriptive case studies recently published by PhiLab (Sidorovska \& Duprez, 2020). This article, however, primarily relies on semi-structured interviews with eight individuals from Project $A$. Each of these individuals is closely involved with one or more foundation-led initiatives that have explicitly challenged mainstream approaches to philanthropic grantmaking. The participants interviewed hold diverse roles and positions within the sector, including foundation chief executive officer $(n=3)$, consultant $(n=1)$, foundation staff $(n=2)$, and Indigenous knowledge keeper $(n=2)$. Each of the eight interviews lasted between 60 and 90 minutes.

This foundation-focused data was complemented with data from Project $B$ that examined how social justice grantee organizations in Montréal and Toronto experienced the philanthropic sector's COVID-19 pandemic response. These COVID-19specific interviews were one component of a larger critical investigation of the experience of social justice grantees within Canadian philanthropy more broadly. This article focuses on 22 interviews drawn from this second research sample. All grantee organizations participating in Project B engage in programming that targets systems and structures of power in addition to more traditional charitable services. These organizations vary in annual expenditure (from $\sim \$ 50,000$ to $\$ 25$ million) and percentage of total annual revenue from philanthropic sources (from $0 \%$ to over $90 \%$ ). The program focus was deliber- 


\section{Saifer, Sidorovska, Litalien, Fontan, \& Duprez (2021)}

ately varied as well, including "marginalized youth" $(n=4)$, "racial justice" $(n=4)$, "refugees and newcomers" $(n=3)$, "inclusion" $(n=3)$, "LGBTQ issues" ( $n=2)$, "Indigenous issues" $(n=2)$, "Islamophobia" $(n=1)$, "women's issues" $(n=1)$, "public education" ( $n=1)$, and "criminal justice reform" $(n=1)$. The total length of each interview ranged from 40 minutes to 90 minutes. Together, this article draws on in-depth semi-structured interviews with 30 individuals, all of which were conducted over Zoom, Skype, or by telephone between May and August 2020.

\section{Data analysis}

Data analysis for this article followed a two-step process (see Figure 1). First, the research lead of Project A developed descriptive case studies (Gomm, Hammersley, \& Foster, 2000) for each of the four initiatives, organized around five topics: a description of the initiative; the rationale behind the initiative; the rationale behind joining the initiative; expected outcomes; and similarities and differences from pre-COVID-19 work. After writing a draft of the descriptive portion of each case study, the research team for Project A met to identify key analytical tensions present within each case study.

\section{Figure 1: Coding process}

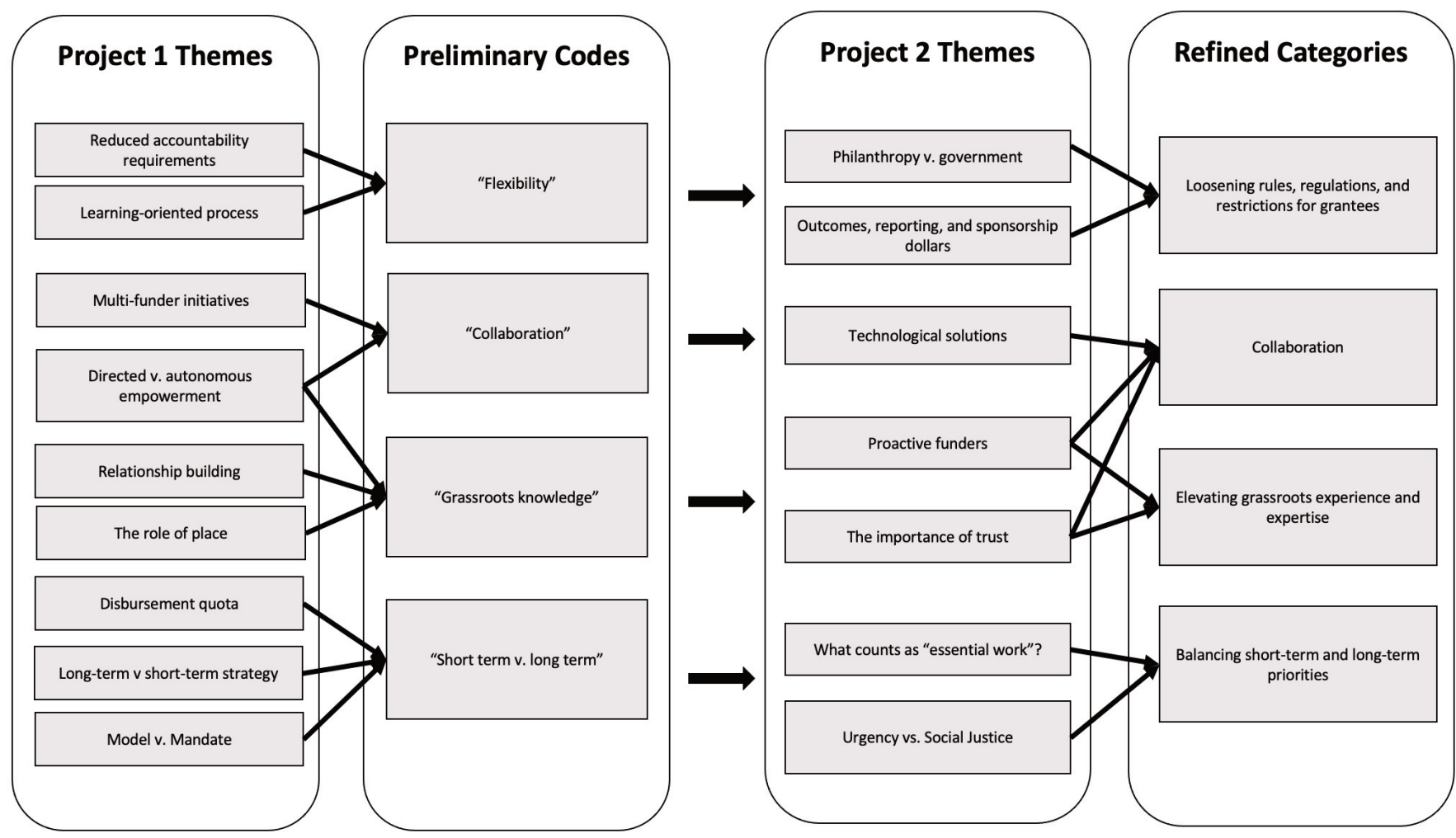

After identifying nine case study themes, the lead researcher of Project A conducted a narrative literature review (Paré, Trudel, Jaana, \& Kitsiou, 2015) using these themes as search criteria in order to situate the case studies in relation to ongoing conversations in the larger foundation literature. Through this process, the researcher consolidated these heterogeneous themes into four higher level descriptive codes (Miles \& Huberman, 1994) that both reflected their data, as well as broad conversations in the extant literature: flexibility, collaboration, grassroots voices, and short-term versus long-term. Once the research leads of Project A and Project B decided to collaborate on this topic, the researcher from Project A shared the four descriptive codes with the lead of Project B who then used them for the deductive coding (Saldaña, 2011) of that project's interview data. The researchers then met to discuss important areas of overlap between the two sets of data, sharing key themes and second-order codes that emerged from their respective coding processes. 


\section{Saifer, Sidorovska, Litalien, Fontan, \& Duprez (2021)}

Some themes were present within both data sets (e.g., flexibility with grantees), while others were closely related (e.g., short-term versus long-term priorities for funders and urgency versus social justice mandates for grantees). After finding areas of overlap and excluding areas without any overlap, the two teams settled on four core categories of grantmaking responses during the COVID-19 pandemic: loosening rules, regulations, and restrictions for grantees; collaboration; elevating grassroots experience and expertise; and balancing short-term and long-term priorities.

\section{CHANGES IN PHILANTHROPIC POLICY AND PRACTICE DURING COVID-19}

\section{Loosening rules, regulations, and restrictions for grantees}

Since March 2020, many grantmaking foundations have loosened the rules, regulations, and restrictions placed on grantees, primarily as they relate to spending, reporting, and application procedures (McCormick, 2000; Philanthropic Foundations Canada, 2020). This has allowed grantees to repurpose project funds to meet their shifting priorities and needs, as well as those of the communities they serve. Across our interviews, grantees reported diverting funds to urgent goods such as personal protective equipment and foodstuffs; emerging needs such as access to digital technologies and one-to-one counselling support; and/or "capacity" dollars to maintain grantee operations, pay staff salaries, and keep their organizations afloat.

In some cases, grantmaking foundations proactively contacted grantees to inform them of this newfound flexibility. The Lawson Foundation (2020), for example, sent a letter to grantees and partners, announcing that: "the Foundation will provide you with increased flexibility in the way you spend the dollars ... so that you may more easily cover urgent costs that are essential to the running of your organization" (para. 3), and further categorized funds as "unrestricted during these challenging times" (para. 3).

In addition to formal announcements, many grantees received informal phone calls and emails from their funders. One interviewee, the executive director of a Montréal-based charity that works with refugees and asylum seekers, recalls being contacted by one such private foundation. "We want to talk to you,' they said. 'Do you need money? Like, right away?'” Another foundation - this one corporate-reached out to him directly and said, "We're planning to send you money in November. But do you need it now?"

Other grantees contacted funders themselves, described the challenges they were facing, and asked for flexibility on existing grants. While these requests were grantee-driven, they often were quite successful. The executive director of a charity that works with youth in under-resourced communities in Toronto explained:

I've reached out to some of our long-term donors and asked if I could convert their project money into sustaining dollars for the organization. And we've actually had a lot of success in doing that. And now we are able to continue to work.

The loosening of restrictions on grantees extended to the area of reporting requirements as well. A November 2020 survey conducted by Philanthropic Foundations Canada (2020) found that 62 percent of respondents modified reporting procedures and deadlines in response to COVID-19. While many of these modifications were initiated by foundations at the start of the pandemic, as of January 2021, they remain prominently displayed on foundation websites and promotional materials.

Grantees found relief in this newfound flexibility around deadlines. "Funders have been really good with extending deadlines and giving you more time to submit grants and things like that," said the artistic director of a Toronto-based arts for social justice charity. They describe their funders as "flexible" and aware that "not everything is going to happen the way that we thought it was going to happen. ... There's been a lot of funders going, 'We're not going to penalize you if you're not able to finish this in time."' 


\section{Saifer, Sidorovska, Litalien, Fontan, \& Duprez (2021)}

Lastly, there has been a significant shift in grantee application requirements, particularly as it pertains to foundations offering COVID-19 emergency grants. As with the lifting of restrictions on spending and reporting for existing grantees, this strategy has been part of an emergency effort in the sector to reduce administrative and management burdens on grantees and ensure that organizational resources can be directed toward program operations rather than administrative tasks (Finchum-Mason, Husted, \& Suárez, 2020). These shifts play out clearly in the application procedures instituted for emergency philanthropic grants. The Lucie et André Chagnon Foundation (2020), for example, created a new category of grants for "organizations interested in submitting a one-time request" (para. 3). These requests are submitted through a written email describing the initiative, how it aims to meet needs directly caused by the pandemic, and an explanation of how it aligns with the specific priorities of the foundation. These changes, where present, indicate a significant departure from time-intensive application processes that can penalize smaller, less professionalized charities without dedicated fundraising staff (Yi, 2010) Taking a step back from such requirements may provide new perspectives on the purpose of grant applications and, if less complex, may be more conducive to realizing a foundation's philanthropic mission.

\section{Collaborating on new programs and initiatives}

Collaboration has played an important role in the foundation response to the COVID-19 pandemic (Philanthropic Foundations Canada, 2020). Foundations have joined forces with community partners, funding partners, and government agencies, to share knowledge and expertise between communities and funders—as well as between funders-to ensure that funders complement each other rather than double efforts; pool funds to craft and scale solutions to address complex systemic challenges; and decrease overhead/administrative costs. As one foundation leader explained,

It was essential that we found ways to share information, and build real transparency and clear collaborations to best meet needs. The openness across foundations to engage in this way was an important evolution in how we work and one I hope we can build upon.

An example of this collaborative process is the Indigenous Peoples Resilience Fund (Community Foundations of Canada, 2021). Indigenous knowledge holders set up the initiative in partnership with several non-governmental funders as a tool to support Indigenous communities during the public health crisis. From the start, this collaborative process was defined by two distinct, yet complementary, conversations: a partner's table that served as an opportunity for funders to learn about Indigenous approaches to philanthropy, and a dialogue among recognized Indigenous knowledge holders and community actors regarding how to immediately and strategically operationalize this philanthropic support. According to one foundation CEO affiliated with the project, the partners table,

allowed funders to learn about the ways in which the Advisory Council of the Indigenous Peoples Resilience

Fund was approaching the work and doing things differently than Western-style philanthropy. It also provides

an entrée for others who are interested in learning, being engaged, and walking alongside the fund.

These dual conversations shaped the current set-up of the Indigenous Peoples Resilience Fund as a collaborative, multifunder, country-wide, and Indigenous-led endeavour.

The pandemic also led to new joint initiatives around large-scale issues within the sector that funders would be unable to tackle on their own. A notable example of this is the GIVE5 pledge: an initiative put forth by several private and community foundations to increase the total amount of funding disbursed by grantmakers across the sector. Currently, the Canada Revenue Agency requires that foundations allocate at least 3.5 percent of their total assets to charitable donees annually. However, organizers of the GIVE5 pledge contended that, given the profound impact of COVID-19 on the charitable sector, foundations should pledge to disburse at least five percent of their total assets during 2020. According to calculations conducted by the GIVE5 steering committee, a sector-wide increase in asset disbursement from 3.5 to five percent would translate into an additional CND\$700 million streamed to the charitable sector in 2020. 


\section{Saifer, Sidorovska, Litalien, Fontan, \& Duprez (2021)}

Despite securing an additional flow of CND $\$ 21.5$ million into the charitable community (Sidorovska \& Duprez, 2020), the GIVE5 campaign failed to achieve its target of 100 signatories. One of the initiators and a member of the GIVE5 steering committee notes that he was partially surprised by the slow reaction in the philanthropic community:

I thought the way it would go is that it would be hard to get the first 10 or 15 , and then it would be easy to get the rest. They would think someone has done the due diligence, so there would need to be good names in the first [place] ... but this is not the way it works in the foundation community.

Nevertheless, the campaign invigorated critical debate regarding the role of foundations in addressing social and economic inequalities, as well as how philanthropic assets-including foundation endowments-can best be used to advance philanthropy's mission. While the argument that philanthropic foundations should be required by law to redirect all of their assets toward impact investments (i.e., the other $96.5 \%$ ) has been floated by critical voices in the sector (e.g., Young, 2019), this call was formalized to some degree with the launch of the \#Other95 campaign on May 11, 2020, by The Circle on Philanthropy and Aboriginal Peoples in Canada (Archie, 2020).

\section{Elevating grassroots expertise and approaches}

At the start of the pandemic, a series of mutual aid projects-emergency support funds and "caremongering" networks, for example-emerged across Canada to channel support directly to individuals and communities most impacted by COVID-19, including those with the highest risk of illness and those facing the greatest barriers to accessing resources and supplies (Paarlberg, LePere-Schloop, Walk, Ai, \& Ming, 2020). The frontline organizations coordinating these mutual aid projects were often best situated to assess urgent needs and channel resources toward relief as situations on the ground continued to unfold; they were also uniquely positioned to translate immediate relief efforts into long-term community capacity-building. And yet, while these frontline groups were providing some of the most direct and urgent support to communities in need, they were (typically) forced to do so without the help of Canada's philanthropic sector. Because these organizations do not have official charitable status, they are legally known as "non-qualified donees" and are barred from receiving grants from foundations within the Canadian Revenue Agency's current regulatory framework.

In response, the early days of the COVID-19 crisis saw a proliferation of discourse in the philanthropic sector around the importance of local grassroots expertise and why "bottom-up" knowledge is essential to emergency grantmaking. Through Zoom webinars, articles, blog posts, and workshops, emphasis was placed on the perspectives of equity-seeking communities-specifically Black- and Indigenous-led organizations and movements (e.g., MacDonald, 2020; Tremblay, 2020) - as well as why grantmaking foundations should support non-qualified donees (e.g., Hibbon, 2020). As researchers and foundations collaborated on toolkits explaining the mechanisms grantmaking foundations can use to direct resources to non-qualified donees (e.g., Kassam, 2020), organizations such as Imagine Canada and political figures such as Senator Ratna Omidvar openly called for the removal of regulatory barriers to philanthropic funding of "non-qualified donees" (e.g., Omidvar, 2017). While the energy around this topic was palpable, it is currently difficult to determine the figures on foundation support of non-qualified donees. A recent survey by Philanthropic Foundations Canada (2020) found that only 19 percent of its members had provided funds to non-qualified donees during the pandemic.

Beyond the question of non-qualified donees, a number of prominent grantmaking foundations set up ad-hoc teams with local leaders and community-based collaborators with the purpose of allocating funds to local communities. The objective of the approach was to have community partners decide where emergency support should go in a timely manner. Apart from ensuring the prompt availability of funding to local communities, this approach allowed foundations to tap into local expertise and ensure funding was tailored to emergency community needs. Other funders used a similar approach by establishing advisory boards made up of grantees and project beneficiaries. One of Canada's largest private foundations relied on an Indigenous Leadership and Insights Circle to guide its COVID-19 recovery and resilience program. The head of programs at the foundation explained the process they followed: 


\section{Saifer, Sidorovska, Litalien, Fontan, \& Duprez (2021)}

We convened the Indigenous Leadership Insight Circle. This was a group of about 20 people and a representative group drawn from community and civil society organizations including young people, educators, and community leaders from across the country. We reached out through networks, came up with a quick terms of reference and said: "Would you be prepared to just help us think through some of these challenges, bring forward ideas, help us source ideas, and make sure that we're paying attention to the right information?" And we were pleasantly surprised that every single one said yes.

In doing so, they were drawing on grassroots knowledge and expertise, rather than dominant top-down approaches, as part of their philanthropic response to the pandemic.

\section{Balancing short- and long-term priorities and goals}

The tension between "provid[ing] emergency funding AND tak[ing] the long view" (Community Foundations of Canada et al., 2020, para. 7) is at the centre of the philanthropic sector's pandemic response. Philanthropy's short-term emergency response arose from the understanding that COVID-19 disproportionately impacts the health and livelihoods of marginalized communities (Canadian Human Rights Commission, 2020; Jenkins, Gadermann, \& McAuliffe, 2020), thereby increasing demand for charitable programs and services (Lasby, 2020). This increased demand for services, however, was coupled with the loss of charitable sector revenue, which placed nonprofits and charities in an increased state of precarity (Johnson et al., 2021; Lasby, 2020). Across the sector, the emergency response of funders was achieved through both the creation of new COVID-19-specific funding opportunities and grant streams (e.g., Lawson COVID-19 Fund [2020]; McConnell COVID-19 Emergency Response Fund [2020]), as well as the aforementioned removal of restrictions on existing grants.

The rationale behind a long-term social change approach is that the societal inequities that COVID-19 revealed and exacerbated existed long before the pandemic began (Van Dorn, Cooney, \& Sabin, 2020). Likewise, these inequities will continue long after philanthropy's emergency response runs its course. Differently put, philanthropy should respond to the crisis of inequities that COVID-19 has revealed and intensified, rather than responding to the COVID-19 crisis, itself. By addressing these longer-term structural issues, philanthropy would help ensure that future crises will not be felt disproportionately in marginalized communities. Throughout the sector, this long-term approach has taken the form of explicit commitments to substantially increase future grantmaking through either lump sums or an increased disbursement quota, and/or the creation of new granting or investment streams geared toward rebuilding the nonprofit and charitable sector and the communities it serves.

In practice, prominent Canadian foundations have instituted varying approaches to attempt to manage the tension between short- and long-term priorities. The Lawson Foundation, for example, created a series of emergency "pop-up community grants," removed all restrictions and reporting requirements on existing grants, and launched several local ad hoc teams to allocate funds in support of organizations in need. The foundation also instituted a phased approach to releasing funds to balance short- and long-term priorities. While emergency funding was disbursed within the first few weeks of the pandemic, these new initiatives continued until the end of the year. This gradual roll-out of funds attempts to balance shortterm urgency with a longer-term outlook on the future needs in the sector.

The Lucie and André Chagnon Foundation (2020a), on the other hand, struck this balance by creating a short-term emergency grant stream for "initiative[s] aimed at meeting needs directly caused by the pandemic" (para. 4), with a bold commitment of disbursing an additional $\$ 150$ million in grants over the next five years "to allow the implementation of long-term structural projects in various regions across Québec" (Chagnon 2020b, para. 5). The McConnell Foundation

has attempted to navigate this tension by pairing its COVID-19 emergency fund with a new stream within its Social Innovation Fund—called Organizational Rebuilding—dedicated to rebuilding the sector post-COVID-19. 


\section{Saifer, Sidorovska, Litalien, Fontan, \& Duprez (2021)}

While foundations responded to the call to balance short-term and long-term approaches through the institution of new policies and programs, grantee experiences of this tension were more complicated. For grantee organizations that typically emphasize long-term social change work, COVID-19 made it imperative that they focus their energy on short-term essential services. The pandemic disproportionately impacted the marginalized communities that social justice grantees serve and advocate for. As a result, these organizations had to put a pause on their social change and advocacy work and prioritize providing essential services and emergency goods. For many charities, this shift in organizational priorities occurred at the very beginning of the pandemic. As the director of philanthropy at one of Toronto's largest LGBTQ advocacy organizations explained:

the [organization] that existed on March 14 [pre-lockdown] doesn't exist anymore. We have completely reorganized our organization. With very few exceptions like myself, the role you had doesn't exist anymore. You are now an essential services worker and we're doing essential services seven days a week. That's all we do. Everyone has been completely retrained. And it's seven days a week—meals, clothing, harm reduction, counselling.

Other grantees report shifting away from core programming toward "community supports," such as one-on-one phone check-ins with community members, or expanding existing services to meet the increased economic, social, and psychological challenges faced by the communities they serve.

The COVID-19 pandemic prompted a shift in grantmaking priorities and approaches. While many of these changes were imagined as momentary responses to the crisis, they nevertheless serve as an opportunity for examining underlying tensions within the dominant philanthropic model. In the process, it is possible to begin to envision and articulate what a more responsive, equitable, and democratic grantmaking practice can look like post-COVID-19.

\section{DISCUSSION}

This section explores some key issues, concerns, questions, and tensions that have emerged from these changes in philanthropic grantmaking. It is organized by scale and theme: organizational-level tensions, accountability; field-level tensions, model; and macro-level tensions, philosophy.

\section{Organizational-level tensions: Accountability}

This research reveals a notable shift in philanthropic policy and practice in response to COVID-19. These findings are corroborated by international studies on early foundation responses to COVID-19, noting comparable changes in granting accountability practices and the grantor-grantee relationship (see Finchum-Mason et al., 2020; Sato, Kumar, Coffman, Saronson, Webster, Gulliver-Garcia, Moore, \& Entcheva, 2020). Most notably, throughout the pandemic, there has been a widespread shift from project-based to core funding, the institution of leaner administrative procedures, and a movement from funder-directed development toward a grantmaking relationship that is, in theory, bottom-up and community-directed. These changes - which prioritize responsiveness to community needs-mark a departure from a top-down philanthropic model where funders direct, streamline, and manage the efforts of community organizations (Christensen \& Ebrahim, 2006; Ostrander, 2007; Shaw \& Allen, 2009). In doing so, these changes have also emphasized the tension between accountability through rationalization and organizational control, and the implications of this approach on the ability of community organizations to respond to community needs in an effective and sustainable way.

The focus on nonprofit activities being more methodically planned and rationalized is part of a wider societal trend to ensure greater sector effectiveness (Bromley, Hwang, \& Powell, 2012; Helmig, Jegers, \& Lasley, 2004). Rooted in the notion that good intentions are not sufficient to ensure social change, the past 30 years have brought a growing emphasis on upward accountability in the sector, manifested through increased scrutiny in reporting, monitoring, and directing grantee 


\section{Saifer, Sidorovska, Litalien, Fontan, \& Duprez (2021)}

efforts (Christensen \& Ebrahim, 2006; Ostrander, 2007). These models have also highlighted power differences between funders and grantees, moving from a mutual, interactive relationship to what Susan Ostrander (2007) refers to as funderdirected philanthropy. However, these increased upward accountability requirements are often found to be too demanding for many nonprofits and eventually threaten downward and lateral accountability, a beneficiary-centric focus, and even mission attainment (Barkan, 2013; Shaw \& Allen, 2009).

Critics of the approach further argue that such levels of external control and direction interfere with organizational capacity for providing prompt and innovative support to the communities they serve, due to demanding administrative procedures that redirect organizational energy away from community needs and development agendas (Benjamin, 2010; Meyer \& Simsa, 2014; Shaw \& Allen, 2009). This is especially true for smaller, less professionalized organizations that lack the human, financial, and administrative resources to respond to this multiplicity of funder-led demands. Coupled with the overall resource dependency of community organizations, these practices also lead to a large imbalance of power between funders and grantees, as grantees become more and more accountable to their funders rather than the communities and individuals they serve (Benjamin, 2010). The literature also suggests that the reduction of upward accountability, as witnessed through the COVID-19 pandemic response, leaves more room for lateral and downward accountability, allowing organizations to focus more on beneficiaries and enabling the achievement of intended outcomes (Benjamin, 2010; Christensen \& Ebrahim, 2009).

In their attempt to address the COVID-19 crisis, grantmaking foundations have encountered this tension between control and accountability procedures on the one hand and effective support for local communities on the other (McCormick, 2020; Philanthropic Foundations Canada, 2020). By introducing more flexibility in management procedures and placing greater power in the hands of grantees to lead the pandemic response, funders have taken a step back from their demands. This ensures that community organizations are better positioned to plan and coordinate their program activities, tend to their operating capacity, and develop interventions that are tailored to specific community needs. In the COVID-19 context, this modified relationship allowed for grassroots organizational resilience and innovation as the sector struggled to respond to increased demands while facing shrinking resources. Despite being an emergency adjustment, the shift also showed the potential to reduce power imbalances and pave the way for a more equitable relationship between funders and grantees (Benjamin, 2010; Christensen \& Ebrahim, 2006).

The long-term implications of these temporary approaches to accountability, program effectiveness, and community empowerment warrant further study, as there are strong indications that a more flexible, partnership-oriented model of collaboration between funders and grantees may end up being more conducive to philanthropic work in pursuit of equity and social justice (Ostrander, 2007). At the same time, this form of support for organizations may also contribute to the sustainability of community support systems and grassroots initiatives that have proven themselves essential during this crisis, making room for effective, locally guided, self-empowering action.

\section{Field-level tensions: Model}

Several initiatives launched in response to the COVID-19 crisis have reinvigorated public discourse around the annual spending and disbursement quota of foundations, the way the full portfolio of philanthropic assets is being used in relationship to the broader foundation mandate, and the rules and regulations stipulating who can legally receive philanthropic grants or donations. These debates reveal a potential contradiction between philanthropy's societal mandate and the legal frameworks that regulate and govern philanthropic giving (Finchum-Mason et al., 2020; Leat, 2016). During COVID-19, discourse surrounding the annual spending requirements of foundations centred on how to balance the long-term protection and growth of philanthropic sector assets with rapid large-scale grantmaking and the opportunity to address immediate social concerns and issues. 


\section{Saifer, Sidorovska, Litalien, Fontan, \& Duprez (2021)}

Since March 2020, there has been an uptick of interest around the disbursement quota-the amount that a philanthropic foundation is legally required to disburse each year in charitable giving. Currently, the disbursement quota is set at 3.5 percent. This number has steadily decreased from five percent in 1975 to 4.5 percent in 1984 to the current amount, which was set in 2004 (Man, 2011). However, as many have argued, the current 3.5 percent quota is marginal when compared with the ten percent rate at which philanthropic assets are growing annually tax-free (Hallward, 2020; Palassio, 2020), and an increase would by no means result in foundations spending away their endowments.

The discussion of the appropriateness of the legally mandated payout minimum is beyond the scope of this article; it touches on questions related to the perpetual existence of foundations and intergenerational social justice (see Leat, 2016; Topeler, 2004). Yet, campaigns such as GIVE5 or Increase the Grants raised important questions around the willingness of foundations to increase their contributions to social causes by increasing the actual payouts, especially in a situation of crisis. Initiatives such as the \#other95 campaign, have asked how the full array of foundation resources can be used to contribute to social causes, based on where foundations invest the remaining 95 percent of their assets. Current policies place no constraints on how foundations manage their endowments. As a result, there is no way to ensure that they aid rather than aggravate issues of inequality and social and environmental injustice. As existing legal frameworks pose minimum requirements on how much-and to where-foundations invest and fund (Barkan, 2010), these conversations have pointed out a possible misalignment between foundation missions and mandates on the one hand and how their assets are used and invested on the other.

Another policy question that received substantial attention throughout 2020-2021, and points to the tension between philanthropic mandate and current regulations, is the legal definition of "non-qualified donees." Throughout the pandemic, grantmaking foundations committed to equity and social justice have prioritized grassroots expertise and knowledge, whether through shared learning sessions, bottom-up research initiatives, community-based advisory teams, or new forms of collaboration. And yet, current regulatory frameworks prohibit the philanthropic support of many frontline organizations best situated to assess urgent needs and channel resources toward relief as situations on the ground continue to unfold. Many of these groups-Black Lives Matter chapters, Solidarity Across Borders, and the Disability Justice Network of Ontario, for example-have also been uniquely positioned to translate immediate relief efforts into long-term community capacity building. As non-qualified donees, they are typically forced to do so from outside Canada's philanthropic ecosystem. These groups are barred from receiving grants from foundations and registered charities within the current regulatory framework of the Canada Revenue Agency. Likewise, foundations and registered charities risk losing their own legal status if they provide grants to non-qualified donees. During the COVID-19 pandemic, some organizations and actors in the philanthropic community have called for a temporary lifting of restrictions on granting to non-qualified donees. Others have begun innovating new strategies and practices for getting around the restrictions on grantmaking to frontline non-qualified donees. Yet, anything but a systemic approach to the issue would mean underestimating the influence and relevance of these organizations, especially considering the growing recognition of their value as both agents of social change and emergency response.

These examples indicate an underlying contradiction between the philanthropic mandate and the existing policies that regulate foundation giving. As future crises are navigated, these field-level tensions deserve further scrutiny to ensure the existing legal framework is better aligned to the mandate and mission of philanthropy to enable greater effectiveness in implementing social change.

\section{Macro-level tensions: Philosophy}

The COVID-19 response of grantmaking foundations has revealed a series of tensions underlying philanthropy's presumed role, function, and mandate within the larger Canadian social policy arena. To be clear, critical philanthropy scholars have 


\section{Saifer, Sidorovska, Litalien, Fontan, \& Duprez (2021)}

explored some of these tensions and contradictions in the past, from the privileged tax treatment of foundations (Raddon, 2008) to the exploitative processes of capital accumulation that produce foundation assets (Saifer, 2020). What is unique about the COVID-19 philanthropic context, however, is the degree to which foundation-led changes in grantmaking practice, themselves, attempt to navigate these core macro-level tensions.

Perhaps most evident in these foundation-led responses is the tension between a "charity approach" and a "social justice" approach to philanthropic work (Burton \& Barnes, 2017; Jensen, 2019) and how this tension uniquely manifests within the COVID-19 context. Here, a charity approach refers to the funding of direct social services to respond to direct social needs, while a social justice approach targets "structural realities [and] the root causes of current economic or political inequality and injustice" (Ramdas, 2011, p. 395). In this way, a social justice approach takes a long-term view to grantmaking, working to abolish the very need for philanthropy by altering "societal institutions so they don't produce the very problems that 'charity' tries to alleviate" (Rabinowitz, 1990, p. xi).

This distinction between a charity approach and a social justice approach as it relates to philanthropy's societal function has been emphasized during the COVID-19 crisis. The sector has delivered a dramatic increase in emergency funding that targets urgent needs such as medical supplies, rising food insecurity, mental health challenges, and increased costs associated with physically distanced service provision (Phillips, Raggo, Pue, \& Mathieson, 2020). From rapid response grantmaking to the Emergency Community Support Fund, funders have mobilized over CND\$172 million through new grants, as well as through the reallocation of existing grants (Philanthropic Foundations Canada, 2020). On the other hand, grantmaking foundations have also demonstrated a keen awareness of how the COVID-19 pandemic is exacerbating already-existing social injustices in Canadian society—particularly around anti-Black racism and economic injustice. This is evidenced by the proliferation of discourse in the sector around "an equitable recovery" (e.g., Nakua, 2021, para. 4) and "philanthropy for racial justice" (e.g., Toronto Foundation, 2020, para. 1), as well as long-term initiatives that aim to identify and combat the societal structures underlying COVID-19's unequal impact. In other words, within grantmaking organizations, there is a push toward addressing not just the COVID-19 crisis but the long-term crises in Canadian society that COVID-19 has revealed and, in some cases, intensified.

This, however, is complicated by the fact that changes in "traditional" charitable grantmaking practice-particularly, around increased flexibility with grantees in response to COVID-19-have been fundamental to the long-term sustainability of social justice grantees during the crisis. This research highlights how social justice grantee organizations have been forced to step away from their social justice and advocacy work, shifting their focus to providing direct services within the communities they work with. As these grassroots organizations, for their part, temporarily transitioned from a social justice approach to a charity approach, they benefitted from the extensive flexibility displayed by many grantmaking foundations that was often absent in their relationships with government funders. In this way, it was through philanthropy's charitable focus-albeit, with a greatly increased degree of flexibility -that grantmaking foundations were able to prop up the work of equity and social justice-focused grantee organizations, both in this moment of emergency and in the long-term.

A related question concerns philanthropy's function vis-a-vis government. While grantmaking foundations have demonstrated a degree of flexibility and trust absent within grantee-government relations, it is still important to note that the bulk of COVID-19 supports-from the Canadian Emergency Response Benefit to the Rapid Housing Initiative-have been led by the government. This is due to the sheer size and scale of government in comparison with the philanthropic sector. Because philanthropy is not capable of funding any universal programs, yet grantmaking foundations receive extremely generous tax treatment that redirects funds away from government programmes, it is necessary to ask what the responsibility of philanthropy is and how philanthropic organizations can be best positioned to help create a more socially and economically just society. 


\section{Saifer, Sidorovska, Litalien, Fontan, \& Duprez (2021)}

\section{CONCLUSION}

This article began by asking how Canadian grantmaking foundations with equity and social justice mandates have responded to the COVID-19 pandemic and what these crisis-driven changes reveal about philanthropy's relation to movements for equity and social justice. It is important to note that because the pandemic is still active, the research team has yet to successfully reach a saturation point. Nevertheless, through the research process, a few recurrent themes took shape via concrete changes in grantmaking policies, programs, and practices, including increased flexibility with grantees, new collaborations, the prioritization of grassroots expertise, and balancing long- and short-term planning. Notably, these changes did not occur within a silo; rather, they closely mapped onto the priority points detailed in the joint statement released in March 2020 by Community Foundations of Canada, Philanthropic Foundations Canada, Environment Funders Canada, and The Circle on Philanthropy and Aboriginal Peoples in Canada (2020). In this way, the observed changes in grantmaking practice suggest the emergence of a collective will within the philanthropic sector-a desire to rethink and reimagine philanthropic grantmaking practice in the face of the COVID-19 crisis.

These changes in grantmaking foundation practice also exposed and emphasized a series of limits and tensions within mainstream approaches to philanthropic grantmaking. At the organizational level, the sector's COVID-19 response highlighted the perpetual tension in the traditional funder-grantee model between top-down control and accountability and a more flexible model that elevates grassroots expertise. In responding to the urgency of the crisis, grantmaking foundations have transitioned from project-based funding to core funding, instituted simplified and sparse administrative procedures, and adopted grantmaking relationships that are increasingly bottom-up and community-directed. The objective of these changes was to relieve the administrative burden on charitable organizations while recognizing the legitimacy of the knowledge, expertise, and approaches of grantee organizations. At the field level, the sector's COVID-19 response emphasized the contradiction between the social, economic, and ecological mission of philanthropic foundations and grantmaking foundations' ability to exist as a charitable entity in perpetuity. New initiatives such as the GIVE5 pledge and the \#other95 campaign signal that some within the sector are seriously grappling with these issues. And yet, it is important to highlight that these two initiatives are both voluntary and short term. Addressing this tension between the mission of philanthropy and the organizational perpetuity of philanthropy would require long-term mandatory regulations that could only be accomplished through changes at the level of policy and charitable tax law. Finally, at the macro level, the sector's COVID-19 response underscored the complicated relationship between a charity approach to philanthropy and a social justice and advocacy approach, asking: what is the purpose of philanthropy and the philanthropic sector within the larger Canadian social policy context within times of crisis?

The pandemic's disproportionate impact on poor, racialized, and Indigenous communities; the elderly; and those living with disabilities can be traced back to pre-COVID-19-era failures in social and public policy infrastructure. These include policies that have contributed to growing wealth inequality, the reduction of government provisions to low-income families, cutbacks to healthcare services, and privatization of long-term care facilities, among many others. In the philanthropic sector's response to the COVID-19 crisis, we can see a shared realization-at least for the time being-that these inequalities were, at best, inadequately addressed by philanthropic grantmaking and, at worst, exacerbated by it. As philanthropic sector rhetoric emerging from the pandemic calls for policies, programs, and practices that contribute to long-term institutional and structural reforms beyond the pandemic, the sector is forced to address these macro-level philosophical tensions around how it can best contribute to these sorts of transformations.

It is on this last point that we wish to end this article. The philanthropic sector has displayed renewed energy, imagination, and will, which has translated into an unprecedented crisis-response. In doing so, the sector has altered the traditional approach to doing philanthropic grantmaking to meet the urgent needs of grantees. If this approach is appropriate for the COVID-19 crisis, why is it not appropriate for the social, economic, and environmental crises that preceded, contributed 


\section{Saifer, Sidorovska, Litalien, Fontan, \& Duprez (2021)}

to, and will outlive the social and economic impact of the pandemic? Can the current emphasis on flexible, leaner, bottom-up, and community-driven grantmaking practice serve as a model for sector-wide action on climate change? Systemic racism? Rapidly increasing wealth inequality and homelessness? Health and educational disparities? How can grantmaking foundations - and the philanthropic sector at large-mobilize and direct the strategies, tools, policies, programs, and learnings from the COVID-19 crisis toward these ongoing crises? These questions are of vital importance to both researchers and practitioners in the sector.

\section{NOTE}

1. The phrase "equity and social justice mandates" is used with acknowledgement that there exists significant debate regarding what this commitment looks like and valid critiques that the very existence of the philanthropic foundation is in direct conflict with ideals of equity and social justice. This article does not focus on evaluating what kinds of philanthropic programs support equity and social justice; rather, it takes as its empirical focus, grantmaking foundations with mandates and missions organized around language of equity, social change, structures of power, and issues of social justice.

\section{WEBSITES}

Black Lives Matter, https://blacklivesmatter.com/

Canadian Philanthropy Partnership Research Network, https://philab.uqam.ca/en

Disability Justice Network of Ontario, https://www.djno.ca/

GIVE5, http://give5.ca/

Increase the Grants, https://increasethegrants.ca

Lawson Foundation, https://lawson.ca/

McConnell Foundation, https://mcconnellfoundation.ca/

Solidarity Across Borders, https://www.solidarityacrossborders.org/en/

\section{REFERENCES}

Akingbola. (2020). COVID-19: The prospects for nonprofit human resource management. Canadian Journal of Nonprofit and Social Economy Research, 11(1), 16-20.

Barkan, J. (2013). Plutocrats at work: How big philanthropy undermines democracy. Social Research, 80(2), 635-652. Barr. (2020). A post-COVID-19 agenda for nonprofit and social economy research. Canadian Journal of Nonprofit and Social Economy Research, 11(1), 7-10.

Benjamin, L.M. (2010). Funders as principals: Performance measurement in philanthropic relationships. Nonprofit Management and Leadership, 20(4), 383-403. doi:10.1002/nml.20001

Boggild, L., \& Hawkesworth, K. (2017). Point/counterpoint: Limited life foundations ensure greater social impact. The Philanthropist. URL: https://thephilanthropist.ca/2017/07/pointcounterpoint-limited-life-foundations-ensure-greater -social-impact/ [September 5, 2020].

Bromley, P., Hwang, H., \& Powell, W.W. (2012). Decoupling revisited: Common pressures, divergent strategies in the U. S. nonprofit sector. M@n@gement, 15(5), 468-501.

Burton, D.O., \& Barnes, B.C. (2017, January 3). Shifting philanthropy from charity to justice. Stanford Social Innovation Review. URL: https://ssir.org/articles/entry/shifting_philanthropy_from_charity_to_justice/ [August 19, 2020]. Canadian Human Rights Commission. (2020). Statement - Inequality amplified by COVID-19 crisis. Ottawa, ON: Canadian Human Rights Commission. URL: https://www.chrc-ccdp.gc.ca/eng/content/statement-inequality -amplified-covid-19-crisis [November 18, 2020]. 


\section{Saifer, Sidorovska, Litalien, Fontan, \& Duprez (2021)}

Chaidez-Gutierrez, F., \& Fischer, R.L. (2013). Reflecting on grantee evaluation accountability to funders: Exploring power dynamics with grassroots organizations in communities of color. Journal of Community Practice, 21(4), 304-326. doi:10.1080/10705422.2013.846286

Cho, C.H., \& Kurpierz, J. (2020). Stretching the public purse: Budgetary responses to COVID-19 in Canada. Journal of Public Budgeting, Accounting and Financial Management, 32(5), 771-783. doi:10.1108/JPBAFM-05-2020-0070

Christensen, R., \& Ebrahim, A. (2006). How does accountability affect mission? The case of a nonprofit serving immigrants and refugees. Nonprofit Management and Leadership, 17(2), 195-209. doi:10.1002/nml

Community Foundations of Canada. (2021). Indigenous Peoples resilience fund. Ottawa, ON, \& Toronto, ON: Community Foundations Canada. URL: https://communityfoundations.ca/initiatives/indigenous-peoples-resilience -fund/ [June 3, 2020].

Community Foundations of Canada, Philanthropic Foundations Canada, Environment Funders Canada, \& The Circle on Philanthropy and Aboriginal Peoples in Canada. (2020). A COVID-19 statement from CFC, PFC, EFC, and The Circle on supporting grantees. Ottawa, ON, \& Toronto, ON: Community Foundations Canada. URL: https://community foundations.ca/a-covid-19-statement-from-cfc-pfc-efc-and-the-circle-on-supporting-grantees/ [April 1, 2020].

Fairfield, K.D., \& Wing, K.T. (2008). Collaboration in foundation grantor-grantee relationships. Nonprofit Management and Leadership, 19(1), 17-44.

Finchum-Mason, E., Husted, K., \& Suárez, D. (2020). Philanthropic foundation responses to COVID-19. Nonprofit and Voluntary Sector Quarterly, 49(6), 1129-1141. doi:10.1177/0899764020966047

Giving USA Foundation. (2009). Giving USA 2009: The annual report on philanthropy for the year 2008. Glenview, IL: Giving USA Foundation.

Gomm, R., Hammersley, M., \& Foster, P. (Eds.). (2000). Case study method: Key issues, key texts. Thousand Oaks, CA: Sage Publications.

Hallward, J. (2020). Foundations can afford to use more of the billions they have collectively accumulated. A new disbursement quota is in order. Policy Options. URL: https://policyoptions.irpp.org/magazines/may-2020/unlocking -the-expanding-wealth-of-charitable-foundations/ [December 2, 2020].

Helmig, B., Jegers, M., \& Lapsley, I. (2004). Challenges in managing nonprofit organizations: A research overview. VOLUNTAS: International Journal of Voluntary and Nonprofit Organizations, 15(2), 101-116.

Hibbon, A. (2020, July 22). Embracing opportunities to work with non-qualified donees: The why and how. Philanthropic Foundations Canada Blog. URL: https://pfc.ca/working-with-non-qualified-donees/ [December 10, 2020].

Imagine Canada. (2020, December 14). More than a third of Canadians will give less to charities this holiday season due to COVID-19: Survey [Press release]. Toronto, ON: Imagine Canada. URL: https://www.imaginecanada.ca len/holiday-giving-survey-2020 [December 14, 2020].

Jenkins, E., Gadermann, A., \& McAuliffe, C. (2020). Mental health impact of coronavirus pandemic hits marginalized groups hardest. The Conversation. URL: https://theconversation.com/mental-health-impact-of-coronavirus -pandemic-hits-marginalized-groups-hardest-142127 [January 29, 2021].

Jensen, C. (2019). The perfect pair or strange bedfellows? Neoliberal social change and social justice philanthropy. Administrative Theory and Praxis, 41(4), 368-387. doi:10.1080/10841806.2019.1643619

Johnson, A.F., Rauhaus, B.M., \& Webb-Farley, K. (2021). The COVID-19 pandemic: A challenge for US nonprofits' financial stability. Journal of Public Budgeting, Accounting and Financial Management, 29(6), 33-46. doi:10.1108 /JPBAFM-06-2020-0076

Kassam, H. (2020). PFC learning series tool 3: A primer for working with non-qualified donees. Montréal, QC: Philanthropic Foundations Canada. URL: https://pfc.ca/wp-content/uploads/2020/09/pfc-primer-working-with-non -qualified-donees_sept2020.pdf [March 6, 2021]. 


\section{Saifer, Sidorovska, Litalien, Fontan, \& Duprez (2021)}

Lasby, D. (2020). Imagine Canada's sector monitor charities \& the COVID-19 pandemic. Toronto, ON: Imagine Canada. URL: https://imaginecanada.ca/sites/default/files/COVID-19\%20Sector\%20Monitor\%20Report\%20 ENGLISH_0.pdf [September 3, 2020].

Leat, D. (2016). Warehouses of wealth: Payout and perpetuity. In Philanthropic foundations, public good and public policy (pp. 85-96). London, UK: Palgrave Macmillan. doi:10.1057/978-1-137-48289-1_7

Lucie and André Chagnon Foundation. (2020). COVID-19. Montréal, QC: Lucie and André Chagnon Foundation. URL: https://fondationchagnon.org/en/covid-19/ [September 5, 2020].

MacDonald, K. (2020). A call to edgewalk: Insights and reflections from PFC webinar: 'COVID-19, Indigenous perspectives \& solutions [Guest blog]. Montréal, QC: Philanthropic Foundations Canada. URL: https://pfc.ca/call -to-edgewalk/ [November 6, 2020].

Man, T. (2011). Disbursement quota reform: The ins and outs of what you need to know [Conference presentation]. National Charity Law Symposium. Toronto, ON: Canada. URL: http://www.cba.org/cba/cle/PDF/CHAR11_Man Slides.pdf [February 10, 2021].

McCormick, B. (2020). How lean funders are responding to COVID-19. Exponent Philanthropy. URL: https://www .exponentphilanthropy.org/blog/how-lean-funders-are-responding-to-covid-19/ [July 8, 2020].

McMullin, C., \& Raggo, P. (2020). Leadership and governance in times of crisis: A balancing act for nonprofit boards. Nonprofit and Voluntary Sector Quarterly, 49(6), 1182-1190. doi:10.1177/0899764020964582

Meyer, M., \& Simsa, R. (2014). Developments in the third sector: The last decade and a cautious view into the future. In M. Freise \& T. Hallmann (Eds.), Modernizing democracy. Associations and associating in the 21st century (203-215). New York, NY: Springer.

Miles, M.B., \& Huberman, A.M. (1994). Qualitative data analysis: An expanded sourcebook. Thousand Oaks, CA: Sage Publications.

Nakua. (2021). An agenda for equitable recovery: Balancing economic outputs with social wellbeing outcomes. [Guest blog]. Ottawa, ON: Imagine Canada. URL: https://imaginecanada.ca/en/360/agenda-equitable-recovery-balancing -economic-outputs-social-wellbeing-outcomes [April 10, 2021].

Omidvar, R. (2021, November 13). 150 profiles: Senator Ratna Omidvar. The Philanthropist Journal. URL: https:// thephilanthropist.ca/2017/11/150-profiles-senator-ratna-omidvar/ [September 22, 2020]

Ostrander, S.A. (2007). The growth of donor control: Revisiting the social relations of philanthropy. Nonprofit and Voluntary Sector Quarterly, 36(2), 356-372. doi:10.1177/0899764007300386

Paarlberg, L.E., LePere-Schloop, M., Walk, M., Ai, J., \& Ming, Y. (2020). Activating community resilience: The emergence of COVID-19 funds across the United States. Nonprofit and Voluntary Sector Quarterly, 49(6), 1119-1128. doi:10 $.1177 / 0899764020968155$

Palassio, C. (2020). Granting during the pandemic: Foundations face increasing calls to increase their expenditures to assist struggling charities. The Philanthropist. URL: https://thephilanthropist.ca/2020/07/granting-during-the-pandemic -foundations-face-increasing-calls-to-increase-their-expenditures-to-assist-struggling-charities/ [March 5, 2021].

Paré, G., Trudel, M.C., Jaana, M., \& Kitsiou, S. (2015). Synthesizing information systems knowledge: A typology of literature reviews. Information \& Management, 52(2), 183-199.

Philanthropic Foundations Canada. (2020, November). 3rd report COVID-19 data mapping series. Montréal, QC: Philanthropic Foundations Canada. URL: https://pfc.ca/wp-content/uploads/2020/11/pfc-covid-survey-report -november-2020_final.pdf [November 30, 2020].

Phillips, S., Raggo, P., Pue, K., \& Mathieson, C. (2020). The work of foundations during COVID-19: Summary report I. Ottawa, ON: Carleton University School of Public Policy and Administration. URL: https://pfc.ca/wp-content /uploads/2020/10/summary-report-foundations-covid-sept-final-1.pdf [October 15, 2020].

Rabinowitz, A. (1990). Social change philanthropy in America. Westport, CT: Greenwood Publishing Group. Raddon, M.B. (2008). Neoliberal legacies: Planned giving and the new philanthropy. Studies in Political Economy, 81(1), 27-48. 


\section{Saifer, Sidorovska, Litalien, Fontan, \& Duprez (2021)}

Ramdas, K.N. (2011). Philanthrocapitalism: Reflections on politics and policy making. Society, 48(5), 393-396.

Reich, R. \& Wimer, C. (2012). Charitable giving and the great recession. Stanford, CA: Stanford Center on Poverty and Inequality. URL: https://inequality.stanford.edu/sites/default/files/CharitableGiving_fact_sheet.pdf [August 14, 2020].

Saifer, A. (2020). Philanthropic nation branding, ideology, and accumulation. Journal of Business Ethics. Online First. doi:10.1007/s10551-020-04567-5

Saldaña, J. (2011). Fundamentals of qualitative research. New York, NY: Oxford University Press USA.

Sato, G., Kumar, S., Coffman, S., Saronson, B., Webster, R., Gulliver-Garcia, T., Moore, K., \& Entcheva, R. (2020). Philanthropy and COVID-19 in the first half of 2020. Washington, DC: Candid and the Center for Disease Philanthropy. URL: https://www.issuelab.org/resources/37232/37232.pdf [September 10, 2020].

Seow, H., McMillan, K., Civak, M., Bainbridge, D., van der Wal, A., Haanstra, C., Goldhar, J., \& Winemaker, S. (2021). \#Caremongering: A community-led social movement to address health and social needs during COVID-19. PloS One, 16(1) (1-11). doi:10.1371/journal.pone.0245483

Shaw, S., \& Allen, J.B. (2009). To be a business and to keep our humanity. A critical management studies analysis of the relationship between a funder and nonprofit community organizations. Nonprofit Management and Leadership, 20(4), 83-96. doi:10.1002/nml

Sidorovska, I. \& Duprez, C. (2020). COVID-19 case studies: Responses from the Canadian philanthropic sector. [Report]. Montréal, QC: Canadian Philanthropy Partnership Research Network. URL: https://philab.uqam.ca /wp-content/uploads/2021/02/Document-complet_29janv-min.pdf [January 30, 2020].

Toepler, S. (2004). Ending payout as we know it: A conceptual and comparative perspective on the payout requirement for foundations. Nonprofit and Voluntary Sector Quarterly, 33(4), 729-738. doi:10.1177/0899764004269318

Toronto Foundation. (2020). Using your philanthropy to advance racial justice [Blog post]. Toronto, ON: Toronto Foundation. URL: https://torontofoundation.ca/using-your-philanthropy-to-fight-racial-injustice/ [February 2, 2021].

Tremblay, F. (2020). Mind the gap: The state of philanthropy and the black community review. PFC [Guest blog]. Montréal, QC: Philanthropic Foundations Canada. URL: https://pfc.ca/mind-the-gap-philanthropy-and-the-black -community-review/ [February 5, 2020].

Van Dorn, A. Cooney, R. \& Sabin, M. (2020). COVID-19 exacerbating inequalities in the US. The Lancet, 395(10232), 1243-1244. doi:10.1016/S0140-6736(20)30893-X

Yi, D.T. (2010). Determinants of fundraising efficiency of nonprofit organizations: Evidence from US public charitable organizations. Managerial and Decision Economics, 31(7), 465-475. doi:10.1002/mde.1503

Young, B. (2019). Foundations ought to be investing in infrastructure. Policy Options. URL: https://policyoptions.irpp .org/magazines/april-2019/foundations-ought-to-be-investing-in-infrastructure/ [March 10, 2020].

\section{ABOUT THE AUTHORS / LES AUTEURS}

Adam Saifer is a Postdoctoral Fellow in Sociology at the Université du Québec à Montréal. Email: saifer.adam @courrier.uqam.ca

Isidora G. Sidorovska is a PhD candidate in the School of Planning at the University of Waterloo. Email: igievski @uwaterloo.ca

Manuel Litalien is Chair of the Department of Social Welfare and Social Development at Nipissing University. Email: manuell@nipissingu.ca

Jean-Marc Fontan is Professor of Sociology at the Université du Québec à Montréal. Email: fontan.jean-marc@uqam.ca

Charles Duprez is a Master's student in Social and Environmental Responsibility at the Université du Québec à Montréal. Email: duprez.charles@uqam.ca . 